\title{
ANALISIS FAKTOR-FAKTOR YANG MEMPENGARUHI PENYERAPAN LULUSAN PROFESI NERS UNIVERSITAS KLABAT
}

\author{
Reagen Mandias \\ Faculty of Nursing Universitas Klabat, Manado, Indonesia \\ rmandias@unklab.ac.id
}

\begin{abstract}
Salah satu tolak ukur mutu suatu program studi adalah kecepatan penyerapan alumni yang dihasilkan dalam dunia pekerjaan. Tujuan dari penelitian ini yaitu untuk menganalisa faktor-faktor apa saja yang mempengaruhi penyerapan lulusan profesi NERS Universitas Klabat di dunia kerja dalam persepsi para alumni. Penelitian ini bersifat deskriptif, yang melibatkan 71 alumni yang meresponse google form yang dikirimkan pada group alumni Fakultas Keperawatan profesi Ners Universitas Klabat. Hasil penelitian menunjukkan bahwa terdapat 20 faktor yang berperan dalam penyerapan lulusan profesi NERS di lapangan pekerjaan, namun lima faktor teratas adalah sikap, ketrampilan, lulusan dari universitas unggulan, sertifikat dan pengetahuan. Berdasarkan hasil penelitian yang ada, peneliti ingin mengajukan saran kepada Fakultas Keperawatan Universitas Klabat, agar memperbanyak praktek untuk pengembangan soft skill para mahasiswa, serta pengembangan kepribadian dalam membentuk sikap atau attitude para calon perawat, mengasah skill para mahasiswa dan melaksakan sertifikasi sesuai kebutuhan pasar sehingga dalam dunia pekerjaan, para alumni akan dengan mudah mendapatkan pekerjaan.
\end{abstract}

Keywords: Analisis Faktor, Penyerapan Lulusan.

\section{Pendahuluan}

Salah satu tolak ukur mutu suatu program studi adalah kecepatan penyerapan alumni yang dihasilkan dalam dunia pekerjaan, itulah sebabnya masing-masing program studi wajib melakukan survei alumni atau lebih dikenal dengan tracer study untuk melihat penyerapan, proses, dan posisi lulusan dalam dunia kerja sehingga kedepannya dapat menyiapkan lulusan yang berkompetensi sesuai dengan kompetensi yang diperlukan di dunia kerja (Wahidin, 2017).

Dari sekian banyaknya program studi yang ada di Indonesia, salah satu yang mendapat animo yang cukup besar dari mahasiswa adalah program studi keperawatan. Menurut Fadillah (2019) dalam Liputan6.com (2019) dan merdeka.com (2019) setiap tahunnya Indonesia melalui prodi keperawatan di seluruh Indonesia menghasilkan sekitar
100.000 perawat. Sementara berdasarkan data dari website Asosiasi Institusi Pendidikan Ners Indonesia - AIPNI (2020), program studi Ners di seluruh Indonesia berjumlah 289

Perawat dalam jumlah besar yang dihasilkan oleh seluruh prodi keperawatan di Indonesia, menuntut setiap prodi untuk menghasilkan lulusan yang berkualitas agar para tamatan dapat memenuhi permintaan pasar. Lestari (2014) menyatakan bahwa untuk menghasilkan lulusan yang berkualitas dan mampu bersaing dalam dunia kerja diperlukan pendidikan keperawatan yang berkualitas pula. Lebih lanjut dikatakan bahwa agar para alumni mampu bersaing dengan perawat-perawat luar negeri, maka kualitas para calon perawat harus bertaraf internasional baik dalam aspek intelektual, tehnikal, pengetahuan, serta mampu memaanfaatkan ilmu pengetahuan dan perkembangan teknologi. 
Tidak bisa dipungkiri bahwa dalam usaha para fresh graduate mencari perkerjaan Indeks Prestasi Kumulatif (IPK) adalah penilaian awal yang digunakan untuk menentukan kompetensi sebelum masuk dalam fase wawancara (Okezone, 2018). Para Interviewer akan menggunakan IPK untuk menyeleksi para calon perawat yang melamar, walaupun pelamar dengan IPK yang tinggi tidak menjamin untuk mendapatkan kerja lebih mudah dibandingkan dengan IPK yang ratarata (Tribun Jogja.Com, 2020).

Faktor lain yang berperan penting dalam penyerapan tenaga kerja perawat adalah kemampuan dalam berbahasa Inggris. Aryo (2018); Anna (2019) menyatakan bahwa tamatan yang mahir berbahasa inggris memiliki peluang yang lebih besar dalam dunia kerja teristimewa dalam dunia kerja multinasional dan global.

Selain memiliki IPK yang tinggi dan mampu berbahasa Inggris yang baik pelatihan teknis juga memiliki peranan yang cukup besar bagi fresh graduate untuk mencari kerja. Pratiwi (2012) menyimpulkan bahwa pelatihan teknis berpengaruh positif dengan kesempatan untuk mendapatkan pekerjaan. Lebih lanjut dikatakan bahwa para fresh graduate yang telah dibekali dengan pelatihan teknis memiliki kecenderungan mendapatkan pekerjaan dalam periode setahun semakin naik $4.17 \%$ lebih dibanding dengan pencari kerja yang tidak pernah mengikuti pelatihan.

Faktor lain yang ikut berpengaruh terhadap cepatnya fresh graduate untuk mendapatkan pekerjaan adalah reputasi dari perguruan tinggi. Semakin tinggi reputasi perguruan tinggi, semakin tinggi kemungkinan lulusannya mendapatkan pekerjaan. Proses untuk lulusan tersebut lebih mudah dan cepat karena, pengusaha menganggap para calon karyawan tersebut memiliki potensi yang lebih besar (Jun, 2017)

\section{Tujuan Penelitian}

Tujuan dari penelitian ini yaitu untuk menganalisa faktor-faktor apa saja yang mempengaruhi penyerapan lulusan profesi NERS Universitas Klabat di dunia kerja dalam persepsi para alumni

\section{Metode Penelitian}

Jenis penelitian yang digunakan dalam penelitian ini adalah deskriptif, dimana peneliti memberikan pertanyaan terbuka kepada para alumni melalui google form. Peneliti membagikan link google form kepada para responden melalui Media Whatsapp Alumni.

Populasi dalam penelitian ini adalah para alumni yang telah bekerja di sejumlah rumah sakit, puskesmas ataupun lahan pekerjaan yang berhubungan dengan profesi keperawatan. Sementara yang menjadi sampel adalah 71 alumni yang bersedia mengisi koesioner dan bekerja sebagai profesi keperawatan.

Pertanyaan yang di berikan adalah : menurut anda, faktor-faktor apa yang membuat anda mendapatkan pekerjaan? Para alumni dapat memberikan jawaban lebih dari satu faktor. Tidak ada tekanan untuk terlibat dalam penelitian ini dan para alumni tidak mencantumkan nama di lembaran koesioner untuk menjamin kerahasisaan jawaban yang diberikan.

\section{Hasil Dan Diskusi}

Pada tabel 1 dapat dilihat bahwa sebagain besar responden (39 responden) bekerja sebagai seorang perawat di berbagai Rumah Sakit, sementara 19 responden bekerja sebagai paramedic di berbagai perusaan baik lokal, nasional maupun internasional, 7 responden bekerja sebagai perawat di klinik-klinik kesehatan, dan 6 responden mendapatkan pekerjaan sebagai pengajar di beberapa instansi pendidikan keperawatan. 
Tabel 1 Frekuensi Tempat Responden Bekerja

\begin{tabular}{|c|c|}
\hline Tempat bekerja & $\mathrm{f}$ \\
\hline Rumah Sakit & 39 \\
\hline Paramedic Perusahaan & 19 \\
\hline Klinik & 7 \\
\hline Pendidikan & 6 \\
\hline $\mathrm{N}$ & 71 \\
\hline
\end{tabular}

Hasil penelitian pada tabel 1 menunjukkan bahwa sebagian besar tamatan profesi ners Universitas Klabat, memilih Rumah Sakit sebagai tempat pertama mereka bekerja untuk mencari pengalaman serta meniti karir ke depan. Berdasarkan Analisa peneliti, ini terjadi karena saat di bangku pendidikan, mahasiswa banyak terpapar dengan lingkungan rumah sakit dan banyak menghabiskan waktu untuk melakukan praktek lapangan di rumah sakit.

Survey yang dilakukan oleh ECPI University pada tahun 2016, terdapat $61 \%$ dari tamatan perawat memilih untuk bekarja di Rumah Sakit ketika tamat dari pendidikan perat. Lebih lanjut dikatakan bahwa alasan memilih rumah sakit sebagai pilihan pertama untuk berkerja, karena di rumah sakit perawat bisa mendapatkan pengalaman dalam hal ketrampilan baik merawat pasien, maupun tindakan medis yang lain. Selain itu kesempatan untuk bisa berkomunikasi dengan pasien, keluarga dan team kesehatan lainnya lebih besar dan banyak peluangnya di rumah sakit.

Tabel 2 menunjukan distribusi frekuensi dari 71 responden yang mengisi pertanyaan faktor-faktor apa yang membuat anda mendapatkan pekerjaan Hasil menunjukkan bahwa terdapat 20 faktor yang membuat para responden mendapatkan pekerjaan. Dari ke 20 faktor tersebut yang tertinggi adalah faktor sikap atau Attitude, dimana ada 42 responden (59\%) yang meyakini merupakan salah satu faktor yang berperan dalam penyerapan alumni dalam dunia pekerjaan. Sementara faktor ketrampilan, lulusan dari universitas unggulan, tersertifikasi dan faktor pengetahuan menempati urutan kedua, ketiga, keempat dan kelima.

Tabel 2 Faktor-Faktor Pendukung Mendapatkan Pekerjaan

\begin{tabular}{lrr}
\hline Faktor & f & Percent \\
\hline Sikap/Attitude & 42 & $59 \%$ \\
Keterampilan/Skill & 17 & $24 \%$ \\
Lulusan Univ. Unggulan & 16 & $23 \%$ \\
Sertifikat & 13 & $18 \%$ \\
Pengetahuan & 10 & $14 \%$ \\
Pengalaman Kerja & 6 & $8 \%$ \\
Kebutuhan tenaga kerja & 5 & $7 \%$ \\
Pendidikan & 5 & $7 \%$ \\
Berserah kepada Tuhan & 4 & $6 \%$ \\
CV yang menarik & 3 & $4 \%$ \\
Masuk dalam kriteria & 3 & $4 \%$ \\
Beragama Advent & 2 & $3 \%$ \\
Keinginan untuk bekerja & 2 & $3 \%$ \\
Keinginan untuk belajar & 2 & $3 \%$ \\
Beragama Advent & 2 & $3 \%$ \\
Memiliki kenalan & 1 & $1 \%$ \\
Kemujuran & 1 & $1 \%$ \\
Lulus tes CPNS & 1 & $1 \%$ \\
Faktor Kesehatan & 1 & $1 \%$ \\
Melewati masa percobaan & 1 & $1 \%$ \\
\hline & &
\end{tabular}

Hasil penelitian ini menunjukan bahwa selain faktor Indeks Prestasi Kumulatif-IPK (Okezone, 2018; Tribun Jogja.Com, 2020), kemampuan dalam berbahasa Inggris (Aryo 2018; Anna 2019), ternyata ada beberapa faktor penting lain yang mempengaruhi tamatan profesi ners keperawatan untuk mendapatkan pekerjaan, seperti sikap dan ketrampilan tamatan. Ternyata sikap dan ketrampilan dari fresh graduate memberikan pengaruh yang baik dalam usaha mereka mendapatkan pekerjaan.

Penelitian yang dilakukan oleh Masoumeh dan Vahid (2017) menyimpulkan 
bahwa perawat yang bekerja di Iran memiliki sikap pada level rata-rata. Sementara yang dibutuhkan adalah perawat yang memiliki sikap pada level di atas rata-rata. Kenechi dan Nyack (2020) menyatakan bahwa bekerja dalam situasi yang serba sibuk merupakan tantangan yang besar untuk mempertahankan sikap yang baik dalam bekerja. Lebih lanjut dikatakan bahwa sikap yang buruk memberikan stress yang tinggi pada lingkungan kerja bahkan pada rekan kerja.

Hasil penelitian ini juga membuktikan bahwa sertifikasi atau pelatihan teknis (Pratiwi, 2012) dan reputasi dari perguruan tinggi (Jun, 2017) merupakan dua faktor penting yang menurut responden berperan penting saat mereka mendapatkan pekerjaan

\section{Kesimpulan Dan Saran}

Para responden yang terlibat dalam penelitian ini bekerja di empat tempat bekerja, yaitu rumah sakit, paramedic perusahaan, klinik dan di instansi Pendidikan. Mayoritas responden memilih bekerja di rumah sakit, sebagai lapangan pekerjaan pertama untuk mencari pengalaman dan meniti karir. Hasil penelitian menunju, bahwa terdapat 20 faktor yang berperan dalam penerimaan fresh graduate di lapangan pekerjaan, namun yang menempati lima posisi teratas adalah sikap, ketrampilan, lulusan dari universitas unggulan, sertifikat dan pengetahuan.

Berdasarkan hasil penelitian yang ada, peneliti ingin mengajukan saran kepada Fakultas Keperawatan Universitas Klabat, agar memasukkan dalam kurikulum menengenai pengembangan soft skill para mahasiswa, serta pengembangan kepribadian dalam membentuk sikap atau attitude para calon perawat lebih baik lagi sehingga dalam dunia pekerjaan, para alumni akan dengan mudah mendapatkan pekerjaan. Selain itu, peneliti juga ingin menganjurkan untuk mengasah skill para mahasiswa melalui praktek dan sertifikasi yang dibutuhkan di dunia pekerjaan, untuk mempersiapkan para alumni di dunia pekerjaan.

\section{Daftar Pustaka}

Anna, L. K. (2019, Juli 12). Mahir Bahasa Inggris Tingkatkan Peluang Kerja. Retrieved from Kompas.com: https://lifestyle.kompas.com/read/2019 /03/01/160500720/mahir-bahasainggris-tingkatkan-peluang-kerja-

Aryo, D. (2018, Agustus 3). Pentingnya Bahasa Inggris dalam Dunia Pekerjaan Era Global. Retrieved from Line Today: https://today.line.me/id/pc/article/Penti ngnya+Bahasa+Inggris+dalam+Dunia +Pekerjaan+Era+Global-GMVBey

ECPI University. (n.d). What Percentage of Nurses Work in Hospitals: Where Else Could I Work as a Nurse? Retrieved from ecpi:

https://www.ecpi.edu/blog/whatpercentage-of-nurses-work-inhospitals-where-else-could-i-work-asa-nurse

Jun, K. (2017). Factors Affecting Employment and Unemployment for Fresh Graduates in China, Unemployment Perspectives and Solutions, . Yang Liu: IntechOpen. doi:DOI: 10.5772/intechopen.69809.

Kenechi, O., \& Nyack, N. M. (2020). Attitude Matters. RN Journal, https://rnjournal.com/journal-ofnursing/attitude-matters-nursing.

Liputan6.com . (2019, Maret 16). Indonesia Kekurangan Tenaga Perawat. Retrieved from Liputan6.com : https://www.liputan6.com/bisnis/read/ 
3918456/indonesia-kekurangantenaga-perawat

Masoumeh, S., \& Vahid, Z. (2017). Nurses'

Attitude towards Professionalization and Factors Influencing It. Journal of Caring Science, 345-357.

Merdeka.Com. (2019, Maret 16). Jumlah Tenaga Perawat di Indonesia di Bawah Standard Dunia. Retrieved from Merdeka.Com:

https://www.merdeka.com/uang/jumla h-tenaga-perawat-di-indonesia-dibawah-standard-dunia.html

Okezone. (2018, November 4). Seberapa Penting IPK dalam Pencarian Kerja? Retrieved from Okezone: https://news.okezone.com/read/2018/1 1/03/65/1972902/seberapa-pentingipk-dalam-pencarian-kerja

Pratiwi, R. (2012). Analisis Faktor Yang Mempengaruhi Lama Mencari Kerja Lulusan Sekolah Menengah dan Pendidikan Tinggi di Indonesia Pada Tahun 2012. Bandung:

http://pustaka.unpad.ac.id/.

Tribun Jogja.Com. (2020, Januari 29). IPK Tinggi Pun Bisa Kalah Saing, Ini Deretan Kesalahan Fresh Graduate Sulit Dapat Kerja. Retrieved from Tribun Jogja.Com: https://jogja.tribunnews.com/2020/01/ 29/ipk-tinggi-pun-bisa-kalah-saing-inideretan-kesalahan-fresh-graduate-sulitdapat-kerja

Wahidin, D. (2020, Maret 27). Retrieved from ristekdikti.go.id: http://pkts.belmawa.ristekdikti.go.id/u pload/1489940569_panduan-bantuanpusat-karir-lanjutan.pdf 